\title{
Tariff Policy and Environmental Qualities of Imported Goods
}

\author{
Horn-In Kou \\ Ming-Chuan University
}

Jin-Li Hu

Tamkang University

\section{Hong Hwang}

National Taiwan University and Sun Yat-Sen Institute

\begin{abstract}
Tariff is a trade measure with both of the trade and environmental effects. This article analyzes the interaction between the tariff rate and the short and long run environmental qualities of imperfectly substitutive imported goods. In the first part, we analyze the effect of changing the tariff rate on the environmental qualities of imported goods. That is, the import country government sets up the tariff rate before the foreign exporters choose their environmental qualities. If improving environmental qualities reduces the rate of decrease of consumers' marginal utilities, then a reduction in the tariff rate results in higher environ-mental qualities; moreover, the long run environ-mental qualities of imported goods will be higher. In the second part, we discuss the effect of environmental quality improvement on the optimal tariff. That is, the foreign exporters choose their environmental qualities before the home country government sets up the tariff rate. When the consumers are not environmentally conscious, whether the importance of environmental qualities is emphasized or not, it is optimal for the government to impose a lower (higher) tariff rate on the high (low) environmental quality imported goods. If
\end{abstract}

\footnotetext{
*Corresponding address: Jin-Li Hu, Dept. of Industrial Economics, Tamkang University, Taipei 25137, Taiwan. Fax: 886-2-26227774. E-mail: jinlihu@yahoo.com.

(C)2001-Center for International Economics, Sejong Institution, All Rights Reserved.
} 
the environmental quality improvement cost is sufficiently higher than the marginal pollution abatement and/ or marginal environmental damage, or if the import country government emphasizes environmental qualities, then the long run tariff rate on high environmental quality imported goods should be lower than that of the short run tariff.

- Key Words: Tariff Policy, Environmental Quality, Pollution in Consumption.

- JEL Classification: F12, Q20, H21.

\section{Introduction}

Trade and environmental issues have been attracting much attention in the international community in recent years. Unilateral trade measures for environmental purposes have caused many trade disputes among the WTO/GATT members. The World Trade Organization (WTO) has therefore established the Trade and Environment Committee to coordinate trade and environmental policies among member economies. The major trade and environmental issues under discussion in the WTO are the regulation of process and production methods, transparency in environmental law and policy, the scope of domestically prohibited goods, etc. (WTO (1996, 1997)).

The GATT agreement requires the generally most-favored-nation treatment (Article I), the national treatment (Article III), antidumping (Article VI), no restrictions other than duties, taxes or other charges (Article XI), restrictions on subsidy (Article XVI), etc. Therefore, GATT restricts the strategic use of trade measures, e.g., tariffs, non-tariff barriers, subsidies, etc. However, GATT Article $\mathrm{XX}$ provides an exception to Article XI, as follows:

"Subject to the requirement that such measures are not applied in the manner which would constitute a means of arbitrary or unjustifiable discrimination...nothing in this agreement shall be construed to prevent the adoption of enforcement by any contracting party of measures: ... b) necessary to protect human, animal, plant life or health ....g) relating to the conservation of exhaustible natural resources of such measures are made effective in conjunction with restrictions on domestic production or consumption."

Therefore, under the name of environmental protection, many countries are resorting to trade measures, for instance, trade bans or restrictions, trade sanctions, green tariffs, border tax adjustments, countervailing duties, mandatory eco-labels, 
and so on. Hence, such trade measures also have environmental effects through affecting firms' decision on such matters as output quantity and environmental quality (Jayadevappa and Chhatre (2000)).

Among various trade measures, tariff is the most commonly seen. Tariff is can be a unit tax or an ad valorem tax on imported goods. The concept of 'green tariff' is to impose different tariff rates on imported goods in order to encourage higher environmental qualities. Usually it is very difficult to measure the emission of imported goods in consumption, not to mention their emission in production. For example, to monitor the exactly emission caused by imported cigarettes is highly costly. Therefore, tariff as an output tax will be more efficient than an emission tax when it is costlier to measure the exact emission of imported goods (Schmutzler and Goulder (1997)).

Both trade and environmental measures have their concomitant trade and environmental effects. The WTO/GATT agreements regulate the trade effects of trade measures, while multilateral environmental agreements deal with the environmental effects of environmental measures. The Standards Code, as part of the GATT system, requires that environmental measures are transparent to all GATT members and that there are no arbitrary or discriminative product and environmental standards. However, whether or not and in what way one country is entitled to apply for trade measures to achieve environmental targets are questions which are still under discussion in the WTO, as is the issue of when a country is allowed to use tariff or non-tariff barriers for environmental purposes.

Three major lines of inquiry are generally to be found in the trade and environment literature. The first is the environmental effect of trade measures, e.g., Anderson (1992), Copeland (1996), d'Arge and Kneese (1972), Koo (1974), Ludema and Wooton (1994, 1997), McGuire (1982), Markusen (1975), Merrifield (1988), Pethig (1976), etc. The second is the trade effect of environmental measures, e.g., Conrad (1993), Kennedy (1994), Lutz (1992), Sartzetakis and Constantatos (1995), van Bergeijk (1991), Walter (1972), etc. And the third is the coordination of trade and environmental policies, e.g., Krutilla (1991), Perroni and Wigle (1994), and Whalley (1991).

However, most of the existing literature on the trade and environmental issues focuses on pollution in production. Pollution in consumption has yet to receive much attention in formal economic analysis, although many countries have already implemented trade measures on the environmental qualities (pollution in consumption) of imported goods. For instance, the U.S. and the European Union 
have imposed either tariff or non-tariff restrictions on imported goods according to their environmental qualities. The green tariff concept proposes a lower (higher) tariff rate on higher (lower) environmental quality imported goods. However, the green tariff also has its trade effect, such as rent shifting. At first glance, it would seem that the green tariff is for "green" purposes. However, strategic environmental policies can be a substitute for strategic trade policies if the multilateral environmental agreements allow for the former and the if trade conventions restrict the latter. In this paper, we set out to prove that a green tariff is still a desirable strategic environmental policy for an importing country, even if neither the government nor consumers take environmental factors into account. Moreover, there is little in the literature on the interaction between firms' decision on environmental qualities and the government of the importing country's choice of the tariff rate. ${ }^{1}$

Many empirical studies support that consumers will concern the consumed good's environmental quality: Blend and Ravenswaay (1999) find that American consumers prefer to buy eco-labeled apples. These eco-labels indicate various ecofriendly practices such as restrained pesticide use, soil conservation, wildlife protection, water conservation, etc. Moreover, Stevens, Ahmad, Ruddell (1998), Wessels, Kline and Anderson (1996), and Wessels, Johnston and Donath (1999) also find similar phenomena in various American markets. Chan (2000) finds that mainland Chinese consumers take into account environmental claim types and the source country's green image. Moreover, the relevant source country's image has significantly affects the effectiveness of environmental advertising.

Following these empirical findings, a few theoretical analyses assume that consumers are willing to pay willing to pay more for goods with higher environmental qualities: Matoo and Singh (1994) make this assumption and show eco-labeling will lead to distinct prices for certified and non-certified goods. Swallow and Sedjo (2000) separate consumers into eco-consumers and on-ecoconsumers. Eco-consumers will change their demand after they receive more information of the good's environmental quality. On the contrary, non-ecoconsumers will not change their demand after they have more information of the good's quality.

\footnotetext{
${ }^{1}$ Although Ludema and Wooton (1994) find that the government of the exporting country has an incentive to promote pollution abatement among its firms, the paper is deficient in that it merely analyzes the interaction between the two governments rather than between the government of the importing country and firms in the exporting country.
} 
The first part of this paper therefore examines the effect of changing the tariff rate on the environmental qualities of the goods exported by the foreign firms. That is, we discuss the question, if the importing country sets up its tariff rate before the foreign exporters choose their environmental qualities, then how does a change in the tariff rate affect these environmental qualities? The second part of this paper analyzes the effect of improving the environmental qualities of imported goods on the optimal tariff rate. That is, if the foreign exporters choose their environmental qualities before the government of the importing country sets up the tariff rate, then how does a change in environmental qualities affect the optimal tariff rate? Moreover, we take the short and long run effects into consideration and apply the Le-Chatelier Principle to analyze the difference between the short and long run effects.

This study is organized as follows: Following the introduction, in Section II we establish a basic model to analyze the above issues. Section III focuses on the effect of the tariff rate on the environmental quality of the imported good. Section IV discusses the optimal tariff rate, taking the short and long run environmental qualities of the imported good into account. Section V concludes the study.

\section{The Basic Model}

In order to simplify the analysis, we assume that there are no domestic firms in the home country (import) market and that there are $n$ foreign firms (exporters). These $n$ foreign firms produce heterogeneous goods and export all of their products to the home country. Following Krishna (1987), we assume the demand function in the home country to be

$$
P^{i}=P^{i}\left(q^{1}, \ldots, q^{n}, n^{i}\right), i=1, \ldots, n,
$$

where $P^{i}, q^{i}$ and $a^{i}$ are, respectively, the $i$ th foreign firm's output price, quantity and environmental quality.

Moreover, we assume that the demand function has the following properties:

(A1) $P_{i}^{i} \equiv \frac{\partial P^{i}}{\partial q^{i}}<0, \quad i=1, \ldots, n$;

(A2) $P_{\sim i}^{i} \equiv \frac{\partial P^{i}}{\partial q^{\sim i}}<0, \quad i=1, \ldots, n$;

(A3) given the same $q, a, P_{i}^{i}<P_{\sim i}^{i}, i=1, \ldots, n$; 
(A4) $P_{i i}^{i}=P_{i \sim 1}^{i}=P_{\sim i \sim i}^{i}=0, i=1, \ldots, n$;

(A5) $P_{a}^{i} \equiv \frac{\partial P^{i}}{\partial a^{i}}>0, i=1, \ldots, n$;

(A6) given the same $q, a, P_{i}^{i}$ are all equal, $P_{\sim i}^{i}$ are all equal, and $P_{a}^{i}$ are all equal, $i=1, \ldots, n$.

Assumption (A1) is common for market demand, i.e., the market demand curve is downward-sloping. Assumptions (A2) and (A3) imply that the products of the $n$ foreign firms are imperfect substitutes and that the self-price effects are larger than the cross-price effects. Assumption (A4) assumes a linear demand functional form for quantity. This is done in order to simplify the mathematical calculation. ${ }^{2}$ Assumption (A5) implies that the willingness to pay of the consumer increases with the environmental quality of the product. ${ }^{3}$ Assumption (A6) is an assumption of symmetry. It implies that the demand functions of the $n$ foreign firms have the same self-price and cross-price effects; the effects of improving environmental quality on product price are also the same.

Furthermore, to focus on the importance of environmental quality in the home country, we assume that all the $n$-firm imported goods generate pollution in consumption. The pollution generated per imported good $i$ is $e=e\left(a^{i}\right), i=1, \ldots, n$, with $e^{\prime} \equiv d e\left(a^{i}\right) / d a^{i}<0 .^{4}$ The above inequality implies that the per output pollution decreases as the environmental quality increases.

Furthermore, the environmental damage function for the home country is $\left.D\left(\sum_{i=1}^{n} e\left(a^{i}\right) q^{i}\right)\right|_{a_{i}=\hat{a}, \forall_{i}}$ with $D^{\prime}>0$ and $D^{\prime \prime}>0 .{ }^{4}$ That is, environmental damage is a strictly convex function of the total pollution caused by imported goods.

As with Conrad (1993), Conrad and Wang (1993), Kennedy (1994), and Schmutzler and Goulder (1997), it is assumed that the marginal production cost is fixed. Furthermore, we assume the marginal production cost $i=1, \ldots, n$, with

\footnotetext{
${ }^{2}$ Because implicit functional form helps us explain the economic intuitions, we still use an implicit functional form in the ensuing discussion in spite of the assumption of a linear demand function.

${ }^{3}$ Generally speaking, $P_{a}^{i}$ increases as consumers become more environmentally conscious. If the consumers are not environmentally conscious, then $P_{a}^{i}=0$.

${ }^{4}$ This functional form implies that all the $n$-firm goods have the same pollution function; i.e., when the environmental qualities are the same, the per output pollution generated is the same.

${ }^{5}$ This assumption implies that the $n$-firms all have identical production cost functions.

${ }^{6} \mathrm{Here}$ we assume that an increase in environmental quality increases marginal production costs. In order to reduce pollution in consumption, manufacturers usually have to spend more on making their products more recyclable, energy saving, bio-degradable, and so on. That is, for each unit of output, a manufacturer has to spend more on raw materials, parts, etc. Therefore, the marginal production costs strictly increase with environmental qualities.
} 
$c^{\prime} \equiv d c\left(a^{i}\right) / d a^{i}>0, c^{\prime \prime} \equiv d^{2} c\left(a^{i}\right) / d\left(a^{i}\right)^{2}>0 .{ }^{5}$ These inequalities imply that when the $n$ firms increase the environmental qualities of their products, the marginal production costs also increase; moreover, the increased magnitudes of the marginal production costs further increase with the environmental qualities. ${ }^{6}$

\section{The Effect of the Tariff Rate on the Environmental Qualities of Imported Goods}

In this section, we analyze the effect of a reduction in the tariff rate on the environmental qualities of imported goods. Our model is a two-stage game: In the first stage, the $n$ foreign exporters simultaneously choose their environmental qualities under the given tariff rate. In the second stage, the foreign exporters engage in Cournot-Nash competition in the home country's market. To solve for the subgame-perfect Nash equilibrium (SPNE) of this game, we follow backward induction. We first solve for the Cournot-Nash output quantities in stage two, and then solve for the Nash equilibrium environmental qualities in stage one.

We also take the short run and the long run situations into consideration. The criterion for distinguishing the short run and the long run is whether or not the number of foreign firms can be adjusted. In the short run, the number of foreign firms is fixed. In the long run, the number of foreign firms can change, and the firms will exit or enter the market until each firm has achieved normal (zero) profit. ${ }^{7}$

\section{A. Short Run Effects}

In this subsection, we consider the short run case in which the number of foreign firms is fixed.

We set up the foreign firms' profit functions as below:

$$
\pi^{i}\left(q^{1}, \ldots, q^{n}, a^{i}, t\right)=P^{i}\left(q^{1}, \ldots, q^{n}, a^{i}\right) q^{i}-t q^{i}, i=1, \ldots, n,
$$

where $t$ is the tariff rate per imported product. ${ }^{8}$

Differentiating Equation (1) with respect to $q^{i}$, we obtain the first-order

\footnotetext{
${ }^{7}$ The short run and long run analysis here is irrelevant to the cost structure, that is, there is no difference between short run and long run production costs.

${ }^{8}$ Here we assume that the home country government imposes a non-discriminative tariff rate. This is a reasonable assumption since the foreign firms in the model are identical in terms of symmetry in their market demand functions; they are also identical in terms of production and pollution functions. Therefore, in equilibrium every foreign exporter chooses the same environmental quality and the home country government imposes a non-discriminative tariff rate.
} 
necessary conditions for the foreign exporters' profit maximization:

$$
\begin{aligned}
\pi_{i}^{i} & \equiv \frac{\partial \pi^{i}\left(q^{1}, \ldots, q^{n}, a^{i}, t\right)}{\partial q^{i}} \\
& =P_{i}^{i} q^{i}+P^{i}-c-t=0, \quad i=1, \ldots, n .
\end{aligned}
$$

Also, we assume the second-order and stability conditions, that is,

$$
\begin{aligned}
& \pi_{i i}^{i} \equiv \frac{\partial^{2} \pi^{i}\left(q^{1}, \ldots, q^{n}, a^{i}, t\right)}{\partial\left(q^{i}\right)^{2}}=2 P_{i}^{i}<0, \quad i=1, \ldots, n ; \\
& \Delta \equiv\left|\begin{array}{cccc}
\pi_{11}^{1} & \pi_{11}^{1} & \ldots & \pi_{11}^{1} \\
\pi_{11}^{1} & \pi_{11}^{1} & & \pi_{11}^{1} \\
\vdots & \vdots & \vdots & \vdots \\
& \pi_{11}^{1} & \cdots & \pi_{11}^{1}
\end{array}\right|>(<) 0, \quad \text { if } \mathrm{n}=\text { even (odd) number }
\end{aligned}
$$

to hold, where $\pi_{i \sim i}^{i} \equiv \partial^{2} \pi^{i}\left(q^{1}, \ldots, q^{n}, a^{i}, t\right) / \partial q^{i} \partial q^{\sim i}$. Solving the $n$ first-order conditions simultaneously, we obtain the equilibrium output quantities:

$$
q^{i}=q^{i}\left(a^{1}, \ldots, a^{n}, t\right), \quad i=1, \ldots, n .
$$

Therefore, the equilibrium output quantity of firm $i$ is a function of its own and the other firms' environmental qualities and the tariff rate. Totally differentiating Equation (2) with respect to $q^{1}, \ldots, q^{n}, a^{1}, \ldots, a^{n}$ and $t$, and applying Cramer's rule, we find the following comparative static results (See Mathematical Appendix A for details):

$$
\begin{aligned}
q_{t}^{i} & \equiv \frac{\partial q^{i}}{\partial t} \\
& =\frac{1}{\Delta} \frac{\Omega}{2 P_{i}^{i}-P_{\sim i}^{i}}\left[1-\sum_{k=1, k \neq i}^{n} \frac{P_{\sim i}^{i}-P_{\sim k}^{k}}{P_{k}^{k}-P_{\sim k}^{k}}\right], \quad i=1, \ldots, n ; \\
q_{a^{i}}^{i} & \equiv \frac{\partial q^{j}}{\partial a^{i}} \\
& =\frac{1}{\Delta} \frac{\Omega}{2 P_{i}^{i}-P_{\sim i}^{i}}\left(P_{i a}^{i} q^{i}+P_{a}^{i}-c^{\prime}\right)\left[1+\sum_{k=1, k \neq i}^{n} \frac{P_{\sim k}^{k}}{2 P_{k}^{k}-P_{\sim k}^{k}}\right], \quad i=1, \ldots, n ;
\end{aligned}
$$




$$
\begin{aligned}
q_{a^{i}}^{i} & \equiv \frac{\partial q^{j}}{\partial a^{i}} \\
& =\frac{1}{\Delta} \frac{\Omega}{2 P_{i}^{i}-P_{\sim i}^{i}}\left(P_{i a}^{i} q^{i}+P_{a}^{i}-c^{\prime}\right) \frac{P_{\sim k}^{k}}{2 P_{k}^{k}-P_{\sim k}^{k}}, \quad i, j=1, \ldots, n, j \neq i ;
\end{aligned}
$$

where $\Omega \equiv \prod_{i=1}^{n}\left(2 P_{i}^{i}-P_{\sim 1}^{i}\right)=\left(2 P_{1}^{1}-P_{\sim 1}^{1}\right)\left(2 P_{2}^{2}-P_{\sim 2}^{2}\right) \ldots\left(2 P_{n}^{n}-P_{\sim n}^{n}\right)$. According to Equation (4), the effect of raising the tariff rate on the output quantities of the foreign exporters is indeterminate and depends on the relative environmental qualities (i.e., $P_{\sim i}^{i}-P_{\sim k}^{i}$ ). However, we can be sure of one thing: When all of the environmental qualities are equal, $q_{t}^{i}=\Omega / \Delta\left(2 P_{i}^{i}-P_{\sim i}^{i}\right)<0$ must hold. As a result, raising the tariff rate must reduce the equilibrium output quantities of all firms.

From Equations (5) and (6), it is seen that the effect of an increase in firm $i$ 's environmental quality on its own and on the other firms' equilibrium output quantities depends on the sign of $P_{i a}^{i} q^{i}+P_{a}^{i}-c^{\prime}$. When $P_{i a}^{i} q^{i}+P_{a}^{i}+-c^{\prime}>[<,=] 0$, an increase in firm $i$ 's environmental quality will make firm $i$ 's output quantity increase (decrease, stay the same) and the other firms' output quantity decrease (increase, stay the same). This is because when one firm improves its environmental quality, its market demand curve shifts outward (i.e., $P_{a}^{i}>0$ ), the marginal production curve shifts upward (i.e., $c^{\prime}>0$ ), and the slope of the market demand curve (i.e., $P_{i a}^{i}$ ) changes. Therefore, if the magnitude of the shift in the demand curve is larger than that of the marginal cost curve (i.e., $P_{i a}^{i} q^{i}+P_{a}^{i}-c^{\prime}>0$ ), then an increase in environmental quality of the imported good will increase the output quantity. In addition, since the $n$ goods are imperfect substitutes, an increase in one firm's output must reduce the other firms' outputs.

We then solve for the equilibrium environmental qualities. Given the equilibrium output quantities in Equation (3), we can rewrite the $n$ firms' profit functions as follows:

$$
\Pi^{i}\left(a^{1}, \ldots, a^{n}, t\right) \equiv \pi^{i}\left(q^{1}\left(a^{1}, \ldots, a^{n}, t\right), \ldots q^{n},\left(a^{1}, \ldots, a^{n}, t\right), i=1, \ldots, n .\right.
$$

Differentiating Equation (7) with respect to $a^{i}$, we get the first-order necessary conditions for the firms' profit maximization:

$$
\begin{aligned}
\Pi_{i}^{i} & \equiv \frac{\partial \Pi^{i}\left(a^{1}, \ldots, a^{n}, t\right)}{\partial a^{i}} \\
& =\frac{\partial \pi}{\partial q^{u}} \frac{\partial q^{i}}{\partial a^{i}}+\sum_{\substack{j \neq 1 \\
\text { Strategic Effect }}} \frac{\partial \pi^{i}}{\partial q^{j}} \frac{\partial q^{j}}{\partial a^{i}}+\frac{\partial \pi^{j}}{\partial a^{i}} \\
0 & \text { Profit Effect }
\end{aligned}
$$




$$
\begin{aligned}
& =\left(P_{i a}^{i}+q_{a}^{i}-c^{\prime}\right) q^{i} \Gamma+\left(P_{a}^{i}-c^{\prime}\right) q^{i} \\
& \quad \text { Strategic Effect } \quad \text { Profit Effect } \\
& =\left(P_{a}^{i}-c^{\prime}\right) q^{i}(1+\Gamma)+P_{i a}^{i}\left(q^{i}\right)^{2} \Gamma=0, i=1, \ldots, n,
\end{aligned}
$$

where $\Gamma \equiv \Omega P_{\sim i}^{i} \Sigma_{j=1, j \neq i}^{n}\left(P_{\sim j}^{j} / 2 P_{j}^{j}-P_{\sim j}^{j}\right) / \Delta\left(2 P_{i}^{i}-P_{\sim i}^{i}\right)$. Firm $i$ 's profit maximization condition guarantees $\partial p^{i} / \partial q^{i}=0$. Firm $i$ 's choice of environmental quality will affect not only its own profit (called 'profit effect') but also outputs of other firms (called 'strategic effect').

Since $\Gamma>0$, the firms' best quality choice must satisfy

$$
P_{a}^{i}-c^{\prime}<(=,>) 0 \text { if } P_{i a}^{i}>(=,<) 0 \quad i=1, \ldots, n .
$$

That is, if the change in the environmental qualities of the imported goods does not affect the rate of decrease of consumers' marginal utilities due to the increase in consumption (i.e., $P_{i a}^{i}=0$ ), then a firm's optimal decision as regards the environmental quality of the product must make the increase in the marginal production cost be equal to the increase in the consumers' willingness to pay at the last unit of improving its environmental quality. If an increase in the environmental qualities slows down the rate of decrease of consumers' marginal utilities (i.e., $\left.P_{i a}^{i}=0\right)$, in order to promote market sales, the foreign exporters will overimprove their environmental qualities, making the increase in the marginal production costs higher than the increase in consumers' willingness to pay. Conversely, if an increase in the environmental qualities speeds up the rate of decrease of consumers' marginal utilities (i.e., $P_{i a}^{i}=0$ ), then the foreign exporters will have much less incentive to improve the environmental qualities of the imported goods, making the increase in the marginal production cost lower than the increase in consumers' willingness to pay.

We assume the second-order conditions, that is,

$$
\Pi_{i i}^{i} \equiv \frac{\partial^{2} \Pi^{i}\left(a^{1}, \ldots, a^{n}, t\right)}{\partial\left(a^{i}\right)^{2}}<0, \quad i=1, \ldots, n .
$$

to hold. Solving the $n$ first-order conditions simultaneously, we derive the equilibrium environmental qualities as follows: ${ }^{9}$

$$
a^{i}=\bar{a}(t ; n), \quad \forall i .
$$

\footnotetext{
${ }^{9}$ Since the market demand functions are symmetric and all the production cost functions are identical, the environmental qualities must be equal in equilibrium.
} 
Substituting Equation (10) into Equation (3), we have the equilibrium output quantities of the foreign exporters:

$$
q^{i}=\bar{q}(t ; n), \quad \forall i
$$

According to the above analysis, we can derive the following proposition.

Proposition 1 In the short run, if $P_{i a}^{i}, P_{\sim i a}^{i}>[=,<] 0$, , then a reduction in the tariff rate increases (does not change, decreases) the environmental qualities of imported goods.

Proof Based on the assumption that all firms are identical, it is sufficient to analyze one representative firm. Referring to Mathematical Appendix B, we have (the superscript $s$ means "short run"):

$$
\left.\frac{d a}{d t}\right|^{s}=-\frac{1}{\Pi_{i i}^{i}} q_{t}^{t} \bar{q}\left\{P_{i a}^{i}+(n-1) P_{\sim i a}^{i}\left[1+(n+1)\left(P_{\sim i}^{i}\right)^{2} \Phi\right]\right\}
$$

where $\Phi \equiv 1 /\left(2 P_{i}^{i}-P_{\sim i}^{i}\right)\left[2 P_{i}^{i}+(n-1) P_{i}{ }_{i}^{i}\right]>0$ This completes the proof.

The economic intuitions implied by Proposition 1 are as follows: As mentioned above, the determination of the equilibrium environmental qualities depends on the relative magnitudes of $P_{a}^{i}, c^{\prime}$ and $P_{i a}^{i}$. That is, the last unit of firm $i$ 's environmental quality must make $P_{a}^{i}, c^{\prime}$ and $P_{i a}^{i}$ satisfy the equilibrium conditions. Thus, provided that the change in the tariff rate makes the relative magnitudes of $P_{a}^{i}, c^{\prime}$ and $P_{i a}^{i}$ change, then the equilibrium environmental qualities will change. Meanwhile, when $P_{a}^{i}$ increases, it increases firm $i$ 's profit after improving its environmental quality; thus, it encourages firm $i$ to improve its environmental quality.

According to the above analysis, we know that given the environmental qualities of imported goods, lowering the tariff rate will increase the firms' output quantities. In addition, $P_{a}^{i}>[=,<] 0$ implies that as consumption increases, consumers' willingness to pay due to the improvement in environmental qualities will increase (stay the same, decrease). In summary, if $P_{i a}^{i}>0$, then lowering the tariff rate increases $P_{i a}^{i}$, thus making the foreign firms improve the environmental qualities of imported goods. ${ }^{10}$

Conversely, if $P_{i a}^{i}<0$, lowering the tariff rate makes the foreign firms decrease the environmental qualities of imported goods. If $P_{a}^{i}=0$, the change in the tariff rate cannot affect the magnitude of $P_{i a}^{i}$ through adjusting the output quantities.

\footnotetext{
${ }^{10}$ Since we assume that the fixed marginal production costs and linear demand functions, i.e., $c^{\prime}$ and $P_{i a}^{i}$, respectively, are not functions of $q$, a change in the tariff rate has no effect on $c^{\prime}$ and $P_{i a}^{i}$ at all.
} 
Thus, no matter how the home country government adjusts the tariff rate, the equilibrium environmental qualities will not be affected.

Lemma 1 If $P_{i a}^{i}, P_{\sim i a}^{i}>[=,<] 0$, an increase in the number of foreign firms makes the foreign firms increase (not change, decrease) the environmental qualities of imported goods.

Proof According to Mathematical Appendix B, we must have

$$
\left.\frac{d a}{d n}\right|^{S}=\frac{1}{\Pi_{i i}^{i}} \frac{\bar{q}}{n-1}\left(P_{a}^{i}-c^{\prime}\right)+P_{\sim i a}^{i} \bar{q}^{2}\left[1+(n-1)\left(P_{\sim i}^{i}\right)^{2} \Phi\right] .
$$

Thus, proving this lemma with Equations (9) and (13) is straightforward.

The economic intuitions of Lemma 1 are as follows. The change in the number of foreign firms changes the degree of market competition and thus the equilibrium output quantities.

Thus, the analysis is quite similar to that of Proposition 1 . If $P_{i a}^{i}>0$, because the increase in the number of foreign firms increases the equilibrium output quantities and thus the profits arising from improving the environmental qualities, the SPNE environmental qualities increase with the number of foreign firms.

\section{B. Long Run Effects}

In the last subsection, we assumed that the number of foreign firms is fixed. In this subsection, we relax this assumption in order to discuss the effect of the tariff rate on the environmental qualities of imported goods when firms are free to enter and exit the market.

In the long run, the foreign firms are free to enter and exit the market. Therefore, the equilibrium conditions consist of both the first-order conditions of profit maximization and normal (zero) profits. The normal profit conditions are

$$
\Pi^{i}\left(a^{1}, \ldots, a^{n}, t\right)=0, i=1, \ldots, n .
$$

Solving Equations (8) and (14) simultaneously, we obtain the long run equilibrium number of foreign firms $n^{*}$ and the environmental qualities of imported goods, thus:

$$
a^{i}=a^{*}(t), \forall i
$$

Substituting Equation (15) into Equation (3), we derive the long run equilibrium output quantities: 


$$
q^{i}=q^{*}(t), \forall i
$$

Lemma 2 In the long run, an increase in the tariff rate reduces the number of foreign firms.

(Proof) From Mathematical Appendix C, it can be shown that (the subscript ${ }_{l}$ means "long run")

$$
\left.\frac{d n}{d t}\right|^{l}=\frac{2 P_{i}^{i}\left(2 P_{i}^{i}-P_{\sim i}^{i}\right) \Phi}{P_{\sim i}^{i} q^{*}}<0 .
$$

Proposition 2 In the long run, if $P_{i a}^{i}, P_{\sim i a}^{i}>[=,<] 0$, lowering the tariff rate makes the foreign exporters increase (not change, decrease) the environmental qualities of imported goods.

(Proof) From Mathematical Appendix C, it can be shown that

$$
\left.\frac{d a}{d t}\right|^{l}=-\frac{1}{\Pi_{i i}^{i}}\left[\Pi_{i t}^{i}+\frac{2 P_{i}^{i}\left(2 P_{i}^{i}-P_{\sim i}^{i}\right) \Phi}{P_{\sim i}^{i} q^{*}} \Pi_{i n}^{i}\right],
$$

where $\Pi_{i t}^{i}=q_{t}^{i} q^{*}\left\{P_{i a}^{i}+\left(n^{*}-1\right) P_{\sim i a}^{i}\left[1+\left(n^{*}+1\right)\left(P_{\sim i}^{i}\right)^{2} \Phi\right]\right\} ; \Pi_{i}^{i n}=-\left(q^{*} / n^{*}-1\right)\left(P_{a}^{o}-c^{\prime}\right)+$ $\left(P_{a}^{o}-c^{\prime}\right)+P_{\sim i a}^{i}\left(q^{*}\right)^{2}\left[1+\left(n^{*}-1\right)\left(P_{\sim i}^{i}\right)^{2} \Phi\right]$. This completes the proof.

To illustrate the long run effect of the tariff rate on environmental qualities and to compare it with the short run effect, we resort to the Le-Chatelier Principle. Rearranging Equation (18) and combining it with Equations (12), (13) and (17), we can express Equation (18) as ${ }^{11}$

$$
\begin{aligned}
\left.\frac{d a}{d t}\right|^{l}= & -\frac{q_{t}^{i} q^{*}}{\Pi_{i i}^{i}}\left\{P_{i a}^{i}+\left(n^{*}-1\right) P_{\sim i a}^{i}\left[1+\left(n^{*}+1\right)\left(P_{\sim i}^{i}\right)^{2} \Phi\right]\right\}, \\
& +\frac{1}{\Pi_{i i}^{i}}\left\{\frac{q^{*}}{n^{*}-1}+\left(P_{a}^{i}-c^{*}\right) P_{\sim i a}^{i}\left(q^{*}\right)^{2}\left[1+\left(n^{*}-1\right)\left(P_{\sim i}^{i}\right)^{2} \Phi\right]\right\}, \\
& \frac{2 P_{i}^{i}\left(P_{i}^{i}-P_{\sim i}^{i}\right) \Phi}{P_{\sim i}^{i} q^{*}} \\
= & \left.\left.\frac{d a}{d t}\right|^{s} \frac{d a}{+d n}\right|^{s} \underbrace{\left.\frac{d n}{d t}\right|^{l} .}_{(-)}
\end{aligned}
$$

The above equation shows that the long run effect of the tariff rate on environmental qualities $\left.(d a / d t)\right|^{l}$ can be decomposed into a short run direct effect $\left.(d a / d t)\right|^{s}$ and an indirect effect $\left.\left.(d a / d t)\right|^{s}(d a / d t)\right|^{l}$ through adjusting the

\footnotetext{
${ }^{11}$ The comparison between the short run and long run effects is conducted under the long run equilibrium number of foreign firms $n^{*}$.
} 
environmental qualities. According to Lemma 2, a rise in the tariff rate reduces the long run number of foreign firms; and by Proposition 1 and Lemma 1, the short run effects of the tariff rate and the number of foreign firms on the environmental qualities are either opposite or are both zero. Therefore, the long run effect of the tariff rate on the environmental qualities of imported goods is always larger than or equal to that of the short run effect, i.e., $\left.|(d a / d t)|^{l}|\geq|(d a / d t)\right|^{s} \mid$.

Propositon 3 If $P_{i a}^{i}, P_{\sim i a}^{i}>[=,<] 0$, when the home country lowers the tariff rate, the long run environmental qualities of imported goods will be higher than (equal to, lower than) those of the short run.

\section{The Effect of Improving Environmental Qualities on the Optimal Tariff Rate}

In this section, we discuss whether the home country government should impose a lower tariff rate if the foreign exporters are active in improving the environmental qualities of imported goods. This section differs from the last since here the environmental qualities have been determined first, with the home country government later setting up the tariff rate in order to maximize the net social surplus of the home country. As with the setup in the last section, the model here is also a two-stage game. In the first stage, the home country government chooses the optimal tariff rate given the environmental qualities. In the second stage, the $n$ foreign firms simultaneously choose the output quantities of imported goods.

\section{A. Short Run Effects}

In this subsection, we analyze the short run optimal tariff policy. First, we solve for the second stage equilibrium quantities. The results are the same as Equations (3), (4), (5) and (6) and can rewritten as

$$
\begin{gathered}
q^{i}=q^{i}(\hat{a}, \ldots, \hat{a}, t)=\hat{q}, \forall i ; \\
q_{t}^{i}=\left(2 P_{i}^{i}-P_{\sim i}^{i}\right) \Phi<0, \quad \forall i ; \\
q_{a^{i}}^{i}=-\left(P_{i a}^{i} \hat{q}^{i}+P_{a}^{i}-c^{\prime}\right)\left[2 P_{i}^{i}+(n-2) P_{\sim i}^{i}\right] \Phi, \quad \forall i ; \\
q_{a^{t}}^{j}=-\left(P_{i a}^{i} \hat{q}^{i}+P_{a}^{i}-c^{\prime}\right) P_{\sim i}^{i} \Phi, \quad \forall i, j, j \neq i ;
\end{gathered}
$$

Second, we solve for the optimal tariff rate. Since we assume that there are no 
domestic firms, the welfare function of the home country consists of consumer surplus, tariff revenue, and the environmental damage caused by pollution. The home country's social welfare function is

$$
\begin{gathered}
\left.G\left(a^{1}, \ldots, a^{n}, t\right)\right|_{a_{i}=\hat{a}, \forall_{i}} \\
\left.\equiv g\left(q^{1},\left(a^{1}, \ldots, a^{n}, t\right), \ldots, q^{n}\left(a^{1}, \ldots, a^{n}, t\right) a^{1}, \ldots, a^{n}, t\right)\right|_{a_{i}=\hat{a}, \forall_{i}} \\
=\sum_{i=1}^{n}\left[\int_{0}^{g^{i}} P^{i}\left(q^{1}, \ldots,,^{i-1}, x,{ }^{i+1}, \ldots q^{n}, a^{i}\right) d x\right. \\
\left.-P^{i}\left(q^{1}, \ldots, q^{n}, a^{i}\right) q^{i}\right]\left.\right|_{a_{i}=\hat{a}, \forall \forall_{i}}+\left.t \sum_{i=1}^{n} q^{i}\right|_{a_{i}=\hat{a}, \forall_{i}}-\left.\beta D\left(\sum_{i=1}^{n} e\left(a^{i}\right) q^{i}\right)\right|_{a_{i}=\hat{a}, \forall_{i}} ;
\end{gathered}
$$

where $\beta$ is a weighting measure of environmental damage to social welfare with $\beta>0$; a higher $\beta$ value implies that the home country government places more emphasis on the environmental qualities of imported goods. Differentiating Equation (23) with respect to $t$ and rearranging Equation (19), we obtain the firstorder condition of the home country's welfare maximization:

$$
\begin{gathered}
\left.G_{t} \equiv \frac{\partial G\left(a^{1}, \ldots, a^{n}, t\right)}{\partial t}\right|_{a_{i}=\hat{a}, \forall_{i}} \\
=\underbrace{\left[-P_{i}^{i} q_{t}^{i} n \hat{q}\right]}_{(-)}+\underbrace{\left[\operatorname{tn} q_{t}^{i}+n \hat{q}\right]}_{(-)}+\underbrace{\left[-\beta D^{\prime} q_{t}^{i} n e(\hat{a})\right]}_{(-)}=0
\end{gathered}
$$

where the three parentheses on the right hand side of the second equality represent the effects of the tariff rate change on consumer surplus, tariff revenue, and environmental qualities, respectively. The first item is negative, which implies that raising the tariff rate adversely affects the consumer surplus. The third item is positive, which implies that raising the tariff rate promotes environmental qualities. The effect of change in the tariff rate on tariff revenue, meanwhile, is indeterminate and depends on the magnitude of the tariff rate and on the number of foreign firms. We assume the second-order conditions to hold, that is,

$$
\left.G_{t t} \equiv \frac{\partial^{2} G\left(a^{1}, \ldots, a^{n}, t\right)}{\partial t^{2}}\right|_{a_{i}=\hat{a}, \forall_{i}}<0
$$

\footnotetext{
${ }^{12}$ Brander and Spencer (1984) show that when the home country government is facing a foreign monopoly, the optimal tariff rate is $t^{*}=q\left(P^{\prime} q_{t}-1\right) / q_{t}$. Thus, when the market demand function is sufficiently "convex", then $P^{\prime} q_{t}-1>0$, making the optimal tariff negative.
} 
The optimal tariff rate can be solved with Equation (24).

Proposition 4 When the home country takes environmental damage into account, the optimal tariff rate is

$$
\hat{t}=\frac{\hat{q}\left(P_{i}^{i} q_{t}^{i}-1\right)+\beta D^{\prime} q_{t}^{i} e(\hat{a})}{q_{t}^{i}}>0 .
$$

(Proof) Since we assume the linear demand functional forms, then by Equation (20) we have $P_{i}^{i} q_{t}^{i}-1=\left[P_{i}^{i}+(n-1) P_{\sim 1}^{i}\right] /\left[2 P_{i}^{i}+(n-1) P_{\sim i}^{i}\right]<0$. Hence, proving this proposition by Equations (20) and (24) is a simple matter.

Proposition 4 can be compared to Brander and Spencer (1984): ${ }^{12}$ According to the above analysis, we know that the sign of the optimal tariff rate depends on the sign of $-\left[\hat{q}\left(P_{i}^{i} q_{t}^{i}-1\right)+\beta D q_{t}^{i} e(\hat{a})\right]$, where $\beta D^{\prime} q_{t}^{i} e(\hat{a})<0$. The determination of the optimal tariff rate, therefore, depends on the sign of $\left(P_{i}^{i} q_{t}^{i}-1\right)$ and the relative magnitudes of $\left(P_{i}^{i} q_{t}^{i}-1\right)$ and $\beta D^{\prime} q_{t}^{i} e(\hat{a})<0$. Therefore, if the market demand function is not linear in output quantity, then $P_{i}^{i} q_{t}^{i}-1<0$ may not hold and we can achieve results similar to those of Brander and Spencer (1984). If the market demand function is sufficiently convex, i.e., if $P_{i}^{i} q_{t}^{i}-1<0$, then the optimal tariff rate may turn negative (i.e., the home country subsidizes the imported goods). However, comparing our results to Brander and Spencer (1984), it is clear that $t<0$ is very unlikely to hold in this study, especially when the home country government heavily emphasizes environmental qualities (when $\beta$ is large), or when the marginal damage of pollution is large (when $D^{\prime}$ is large). This is because in this study, the home country government also takes environmental damage into account. Therefore, the decision on the optimal tariff rate has to balance concerns of the effects of the tariff on raising the consumer surplus and tariff revenue and on reducing pollution $(e(\hat{a}) \hat{q})$. Thus, it is less likely that the optimal tariff rate will be negative when the government is concerned about environmental damage.

As already mentioned, the optimal tariff rate is a function of the environmental qualities and the number of foreign firms. By assuming that $D^{\prime \prime}=0$, we come up with the following proposition.

Proposition 5 In the short run, the effect of improving environmental qualities on the optimal tariff rate is indeterminate and depends on the signs of $P_{i a}^{i}$ and $P_{\sim i a}^{i}$ and the relative magnitudes of $P_{a}^{i}, c^{\prime}, \beta, D^{\prime}$, and $\left|e^{\prime}\right|$. The home country government should impose a lower tariff rate on high environmental quality imported goods, if $P_{i a}^{i}, P_{\sim i a}^{i}>0$ and get larger, if $P_{a}^{i}$ gets smaller, or if $c^{\prime}, \beta, D^{\prime}$ and $\left|e^{\prime}\right|$ get larger. Otherwise, the home country government should impose a higher tariff rate on 
high environmental quality imported goods.

Proof From Mathematical Appendix D, it can be shown that

$$
\left.\frac{d t}{d a}\right|^{s}=\frac{1}{2-P_{i}^{i} q_{t}^{i}}\left\{\left(1-P_{i}^{i} q_{t}^{i}\right)\left(P_{a}^{i}-c^{\prime}\right)+\beta D^{\prime} e^{\prime}-\hat{q}\left[P_{i}^{i} q_{t}^{i} P_{i a}^{i}+(n-1) P_{\sim i a}^{i}\right]\right\}
$$

Thus, $\left.(d t / d a)\right|^{s}<0$ is more likely to hold if $P_{i a}^{i}$ and $P_{\sim i a}^{i}>0$ and get larger, if $P_{a}^{i}$ gets smaller, or if $c^{\prime}, \beta, D^{\prime}$ and $\left|e^{\prime}\right|$ get larger. Otherwise, $\left.(d t / d a)\right|^{s}>0$ is more likely to hold.

The economic intuitions of Proposition 5 are as follows: When the foreign firms promote the environmental qualities of their products, there are four effects on the home country's welfare level: First, it directly increases consumer utilities $\left(P_{a}^{i}>0\right)$. Second, it increases the marginal production cost of the foreign exporters $\left(c^{\prime}>0\right)$ and thus increases the price of imported goods. The first effect increases the consumer surplus but the second effect decreases the consumer surplus. As a result, when $P_{a}^{i}$ is small or when $c^{\prime}$ is large, if the foreign firms increase the environmental qualities of imported goods, then the home country government should lower the tariff rate to compensate for the loss in the consumer surplus. Third, it affects the rate of decrease of consumers' marginal utilities $\left(P_{i a}^{i}\right.$ and $\left.P_{\sim i a}^{i}\right)$. Therefore, when $P_{i a}^{i}$ and $P_{\sim i a}^{i}>0$, it implies that the improvement in environmental qualities slows down the rate of decrease of the marginal utilities and helps raise the consumer surplus. Therefore, when $P_{i a}^{i}$ and $P_{\sim i a}^{i}>0$ and get larger, if the environmental qualities increase, the home country government has an incentive to reduce the tariff rate in order to increase imports and thereby increase the consumer and social surpluses. And fourth, it reduces pollution $\left(e^{\prime}<0\right)$ and environmental damage. Thus, as $\left|e^{\prime}\right|$ gets larger, pollution decreases, and the home government has less of an incentive to reduce pollution by imposing a tariff. As a result, the optimal tariff rate decreases. Similarly, as $D^{\prime}$ gets larger, environmental damage increases. As $\beta$ gets larger, the home country government emphasizes environmental qualities more heavily. Therefore, as $D^{\prime}$ or $\beta$ gets larger, the improvement in environmental qualities can more effectively reduce the negative impact of environmental damage on the welfare level. Hence, as $\left|D^{\prime}\right|$ or $\beta$ gets larger, pollution increases, and the home government has more of an incentive to reduce pollution by imposing a tariff. As a result, the optimal tariff rate increases.

\footnotetext{
${ }^{13}$ Traditional trade theory holds that when the market is close to perfect competition, imposing a tariff will make the level of social welfare go down.
} 
Lemma 3 When the number of foreign exporters increases, the optimal tariff rate of the home country increases. Otherwise, the optimal tariff rate decreases.

(Proof) From the Mathematical Appendix D, it can be shown that

$$
\left.\frac{d t}{d n}\right|^{s}=\frac{P_{\sim i}^{i} \hat{q}}{2-P_{i}^{i} q_{t}^{i}}>0 .
$$

The economic intuitions of Lemma 3 are as follows. When the number of foreign exporters increases, on one hand it increases the optimal tariff rate, which hurts the consumer surplus. ${ }^{13}$ While on the other hand, it increases pollution and thus increases the optimal tariff rate, which in turn reduces environmental damage by reducing imports. Let us further consider the tariff revenue. Although a rise in the tariff rate decreases imports, under the assumption of linear market demand functions (i.e., that an increase in the tariff rate will not reduce imports too drastically), tariff revenue may still increase as the number of foreign firms increases. As the number of foreign exporters increases, the benefits of raising the tariff rate outweigh the associated losses, and hence the optimal tariff rate increases with the number of foreign exporters.

\section{B. Long Run Effects}

In this subsection, we analyze the long run effect of environmental qualities on the optimal tariff rate and compare the short and long run effects. In addition to profit maximization, the long run equilibrium conditions also contain normal profit conditions, that is,

$$
\left.\Pi^{i}\left(a^{1}, \ldots, a^{n}, t\right)\right|_{a_{i}=\hat{a}, \forall_{i}}=0 \quad i=1, \ldots, n
$$

Solving Equations (24) and (27), we obtain the long run equilibrium number of foreign firms $\tilde{n}$ and the tariff rate $\breve{t}$. Substituting these equilibrium outcomes into Equation (19), we get the long run equilibrium individual firm's output $\breve{q}$. Through the above analysis, we obtain Lemma 4.

Lemma 4 In the long run, the effect of improving environmental qualities on the number of foreign firms is indeterminate. It is more likely that the number of foreign firms will increase with an improvement in environmental qualities, if $P_{i a}>0$ and gets larger, if $P_{a}^{i}, \beta$ and $\left|e^{\prime}\right|$ get larger, or if $c^{\prime}$ gets smaller. Otherwise, it is more likely that the number of foreign firms will decrease with an improvement in environmental qualities.

(Proof) According to Mathematical Appendix E, we have 


$$
\left.\frac{d n}{d a}\right|^{l}=-\frac{P_{i}^{i} q_{t}^{i}}{P_{\sim i}^{i} \check{q}^{i}\left(2+P_{i}^{i} q_{t}^{l}\right)}\left[2\left(P_{a}^{i}-c^{\prime}\right)-2 \beta D^{\prime} e^{\prime}+\check{q} P_{i a}^{i}\right]
$$

Therefore, we can show that it is more likely that $\left.(d n / d a)\right|^{l}>0$ will hold if $P_{a}^{i}>0$ and increases, if $P_{i a}^{i}, \beta$ and $\left|e^{\prime}\right|$ increase, or if $c^{\prime}$ decreases. Otherwise, it is more likely that $\left.(d n / d a)\right|^{l}<0$ will hold.

The economic intuitions of Lemma 4 are as follows. The long run effect of improving environmental qualities on the number of foreign firms depends on how the improvement affects firm profits. If improving environmental qualities increases profits, then the number of foreign firms will increase due to the entry of more firms into the market. Otherwise, the number of foreign firms will decrease. The effect of improving environmental quality on firms i's profit can be decomposed into two effects. The first effect is the direct effect. The direct effect raises the market price $\left(P_{a}^{i}>0\right)$ and increases marginal production costs $\left(c^{\prime}>0\right)$. The second effect is the indirect effect. The indirect effect changes the tariff rate $\left(\left.(d t / d a)\right|^{s}\right)$ and thus affects firm profits. Proposition 5 it shows that it is more likely that improving environmental qualities will reduce the optimal tariff rate and increase firm profits, if $P_{a}^{i}, P_{i a}^{i}>0$ and get larger, if $\beta, D^{\prime}$ and $\left|e^{\prime}\right|$ get larger, or if $c^{\prime}$ gets lower. In sum, it is more likely that improving environmental qualities increases the long run number of foreign firms, if $P_{a}^{i}, P_{i a}^{i}>0$ and get larger, if $\beta, D^{\prime}$ and $\left|e^{\prime}\right|$ get larger, or if $c^{\prime}$ gets lower. According to the above analysis, we may state the following proposition.

Proposition 6 The long run effect of improving environmental qualities on the optimal tariff rate depends on the signs of $P_{i a}^{i}$ and $P_{\sim i a}^{i}$ and the relative magnitudes of $P_{a}^{i}, c^{\prime}, \beta, D^{\prime}$ and $\left|e^{\prime}\right|$. The direction of the long run effect is similar to that of the short run effect.

(Proof) By Mathematical Appendix E, we obtain

$$
\begin{aligned}
\left.\frac{d t}{d a}\right|^{l}= & -\frac{1}{2+P_{i}^{i} q_{t}^{i}}\left\{\left(1+P_{i}^{i} q_{t}^{i}\right)\left(P_{a}^{i}-c^{\prime}\right)+\beta D^{\prime} e^{\prime}-\check{q} P_{i a}^{i}\right. \\
& {\left.\left[P_{i}^{i}+(\check{n}-1) P_{\sim i}^{i}\right] P_{i a}^{i}-\check{q}(\check{n}-1) P_{\sim i a}^{i}\right\} }
\end{aligned}
$$

Therefore, we can show that $\left.(d t / d a)\right|^{l}<0$ is more likely to hold if $P_{i a}^{i}, P_{\sim i a}^{i}>0$ and get larger, if $P_{a}^{i}$ gets smaller, or if $c^{\prime}, \beta, D^{\prime}$ and $\left|e^{\prime}\right|$ get larger. Otherwise, $\left.(d t / d a)\right|^{l}>0$ is more likely to hold. 
We now apply the Le-Chatelier Principle to illustrate the short and long run effects of improving the environmental qualities of imported goods on the optimal tariff rate. Using Equations (25), (26) and (28), we can rewrite Equation (29) as

$$
\begin{gathered}
\left.\frac{d t}{d a}\right|^{l}=\frac{1}{2+P_{i}^{i} q_{t}^{i}}\left\{\left(1+P_{i}^{i} q_{t}^{i}\right)\left(P_{a}^{i}-c^{\prime}\right)+\beta D^{\prime} e^{\prime}-\right. \\
\left.\check{q}\left[P_{i}^{i} q_{t}^{i} P_{i a}^{i}+(\check{n}-1) P_{\sim i}^{i}\right]\right\}+\left(\frac{-P_{\sim i}^{i} \check{q}}{2-P_{i}^{i} q_{t}^{i}}\right)^{s} \\
\left\{\frac{-P_{i}^{i} q_{t}^{i}}{P_{\sim i}^{i} \check{q}\left(2+P_{i}^{i} q_{t}^{i}\right)}\left[2\left(P_{a}^{i}-c^{\prime}\right)-2 \beta D^{\prime} e^{\prime}+\check{q} P_{i a}^{i}\right]\right\}=\left.\underline{\frac{d t}{d a}}\right|^{s}+\underbrace{\left.\left.\frac{d t}{d n}\right|^{s} \frac{d n}{d a}\right|^{l}}_{(+)}
\end{gathered}
$$

This equation shows that the long run effect on the optimal tariff rate of improving environmental qualities $\left.(d t / d a)\right|^{l}$ can be decomposed into the direct effect $\left(\left.(d t / d a)\right|^{s}\right)$ and the indirect effect, which affects the long run number of foreign firms $\left.\left.(d t / d a)\right|^{s}(d t / d a)\right|^{l}$.

According to Lemma 3, the changes in the number of foreign firms and the optimal tariff rate go in the same direction. However, the effects of improving environmental qualities on the tariff rate and on the number of foreign firms may go in either the same or the opposite direction. Therefore, the long run effect of improving environmental qualities on the tariff rate is indeterminate.

In the extreme situation when the consumers are not environmentally conscious at all, i.e., when $P_{a}^{i}=0$, we can derive the following proposition.

Proposition 7 When people are not environmentally conscious, that is, when $P_{a}^{i}=0$,

(1) Whether in the short run or the long run, the home country government should impose a low (high) tariff on high (low) environmental quality imported goods.

(2) Whenever the environmental quality improvement cost $\left(c^{\prime}\right)$ gets larger, or the abatement technology $\left(\left|e^{\prime}\right|\right)$, environmental damage $\left(D^{\prime}\right)$ and the home country government's emphasis on environmental qualities $(\beta)$ get smaller, then the long run optimal tariff on high (low) environmental quality imported goods should be lower (higher) than that of the short run optimal tariff.

(Proof) When $P_{a}^{i}=0$, by Equations (25) and (29), we obtain:

$$
\left.\frac{d t}{d a}\right|^{l}=\frac{1}{2-P_{i}^{i} q_{t}^{i}}\left[-c^{\prime}\left(1-P_{i}^{i} q_{t}^{i}\right)+\beta D^{\prime} e^{\prime}\right]<0
$$




$$
\begin{gathered}
\left.\frac{d t}{d a}\right|^{l}=\frac{1}{2+P_{i}^{i} q_{t}^{i}}\left[-c^{\prime}\left(1+P_{i}^{i} q_{t}^{i}\right)+\beta D^{\prime} e^{\prime}\right]<0 ; \\
\left.\frac{d t}{d a}\right|^{l}-\left.\frac{d t}{d a}\right|^{s}=\frac{-2 P_{i}^{i} q_{t}^{i}}{\left(2-P_{i}^{i} q_{t}^{i}\right)\left(2+P_{i}^{i} q_{t}^{i}\right)}\left(c^{\prime}+\dot{\beta} D^{\prime} e^{\prime}\right) .
\end{gathered}
$$

Therefore, $\left.(d t / d a)\right|^{l}<\left.(d t / d a)\right|^{s}<0$ is more likely to hold if $c^{\prime}$ gets larger, or if $\left|e^{\prime}\right|, D^{\prime}$ and $\beta$ get smaller. Otherwise, $\left.(d t / d a)\right|^{s}<\left.(d t / d a)\right|^{l}<0$ is more likely to hold.

Thus, whether the consumers are environmentally conscious or not and whether it is in the short run or the long run, the home country government should always impose a low (high) tariff rate on high (low) environmental quality imported goods. This is because a green tariff policy has both trade and environmental effects. Furthermore, even if there are no environmental concerns, a green tariff policy can still be adopted for trade purposes such as rent shifting, etc. Under the name of environmental protection, governments are tempted to employ tariffs or NTBs in order to extract rents and snatch profits from foreign countries. Environmental tariff policy may hence easily be misused for strategic trade concern.

\section{Conclusion}

As an economy develops, people demand higher environmental qualities. Environmental protection has become an important economic policy target in the modern political scene. Coordination between trade and environmental policies has in particular become a crucial issue under the growing importance of free trade and environmental protection in the global community.

The main purpose of this paper is to discuss the interaction between the tariff rate and the environmental qualities of imported goods. Our major conclusions are as follows: First, when the home country government takes environmental damage into account, the optimal tariff rate is usually positive. Second, the foreign exporters' choice of environmental qualities when the home country adjusts the tariff rate depends on how the improvement in environmental qualities affects the rate of decrease of consumers' marginal utilities. If the improvement in environ-mental qualities slows down (does not change, speeds up) the rate of decrease of consumers' marginal utilities, then lowering the tariff rate will make foreign exporters increase (not change, decrease) the environmental qualities in both the short run and the long run; the long run environmental qualities are higher than 
(equal to, lower than) those of the short run. Therefore, a green tariff policy may also turn out to increase environmental damage if the policy is badly designed. Third, the determination of the optimal tariff rate depends on the degree of environmental consciousness among consumers and how the improvement in environmental qualities affects the rate of decrease of consumers' marginal utilities, environmental quality improvement costs, the home country government's emphasis on environmental qualities, marginal environmental damage, marginal pollution abatement, etc. However, whether the consumers are environmentally conscious or not and whether in the short run or the long run, the home country government should always impose a low (high) tariff rate on high (low) environmental quality imported goods.

This paper has several deficiencies: First, we assume that there are no domestic firms. When the home country government imposes the optimal tariff rate, we do take the profits and pollution of the domestic firms into account. This setup is perfectly in line with GATT/WTO rules, because the domestic government imposes a tax on foreign products without violating the national treatment principle (GATT Article III). However, if the importing country is highly developed and its domestic firms' environmental qualities are high, our con-clusions will still stand, no matter whether we take the domestic firms into account or not. A more controversial type of green tariff policy is that the home country government discriminates among domestic and foreign firms according to differences in environmental qualities of the respective products. Second, here we take into account only one policy instrument, the tariff. In reality, the home country government may also choose other policy instruments, for example, environmental standards on the imported goods. It will be interesting to think about whether alternatives will induce foreign firms to invest more in environmental qualities. Combination of various instruments is also an important trade and environment issue. Third, this study establishes a one-government model. If we expand the model into a two-government model, then it is not clear whether the foreign country government will have the incentive to change the environmental qualities of its exports. In this case, environmental dumping in which countries export goods with low environmental qualities may occur. Fourth, if the two governments can both determine their optimal tariff rate, then the results under mutual favor or retaliation will be quite different. These interesting issues could be addressed in future research. 


\section{Mathematical Appendices}

(Mathematical Appendix A): The Derivation of $\boldsymbol{q}_{t}^{i}, \boldsymbol{q}_{\boldsymbol{a}^{i}}^{i}$ and $\boldsymbol{q}_{\boldsymbol{a}^{i}}^{j}$

Totally differentiating Equation (2) with respect to $q^{1}, \ldots, q^{n}, q^{1}, \ldots, a^{n}$ and $t$, we obtain:

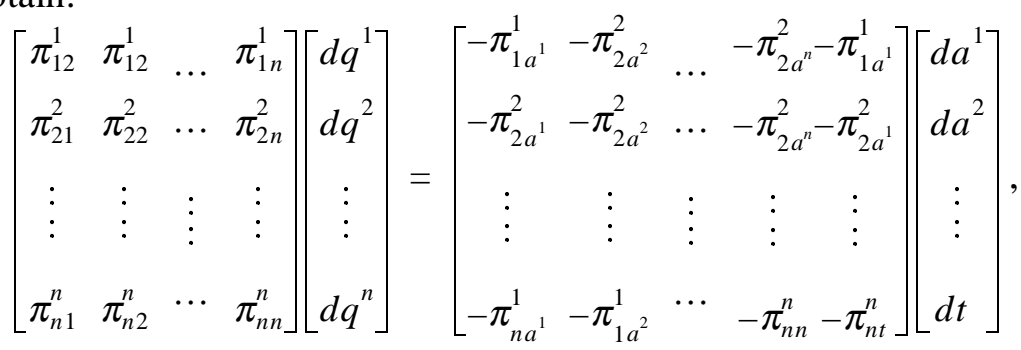

where

$$
\begin{aligned}
& \pi_{i i}^{i} \equiv \frac{\partial^{2} \pi^{i}\left(q^{1}, \ldots, q^{n}, a^{i}, t\right)}{\partial\left(q^{i}\right)^{2}}=2 P_{i}^{i}<0 ; \\
& \pi_{i \sim i}^{i} \equiv \frac{\partial^{2} \pi^{i}\left(q^{1}, \ldots, q^{n}, a^{i}, t\right)}{\partial q^{i} \partial q^{\nu^{i}}}=2 P_{i}^{i}<0 ; \\
& \pi_{i a^{i}}^{i} \equiv \frac{\partial^{2} \pi^{i}\left(q^{1}, \ldots, q^{n}, a^{i}, t\right)}{\partial q^{i} \partial a^{\sim i}}=P_{i a}^{i} q^{i}+P_{a}^{i}-c^{\prime} ; \\
& \pi_{i a^{-i}}^{i} \equiv \frac{\partial^{2} \pi^{i}\left(q^{1}, \ldots, q^{n}, a^{i}, t\right)}{\partial q^{i} \partial q^{\sim i}}=0 ; \\
& \pi_{i t}^{i} \equiv \frac{\partial^{2} \pi^{i}\left(q^{1}, \ldots, q^{n}, a^{i}, t\right)}{\partial q^{i} \partial t}=-1 .
\end{aligned}
$$

Applying Cramer'srule, we then derive

$$
\begin{aligned}
& q_{t}^{1}=\frac{1}{\Delta}\left[\begin{array}{ccccc}
1 & P_{2}^{1} & P_{3}^{1} & \ldots & P_{n}^{1} \\
1 & 2 P_{2}^{2} & P_{3}^{2} & \ldots & P_{n}^{2} \\
1 & P_{2}^{3} & 2 P_{3}^{3} & \cdots & P_{n}^{3} \\
\vdots & \vdots & \vdots & \vdots & \vdots \\
\vdots & \vdots & \vdots & \vdots \\
1 & P_{2}^{n} & P_{3}^{n} & \cdots & 2 P_{n}^{n}
\end{array}\right] \\
& =\frac{1}{\Delta} \frac{\Omega}{2 P_{1}^{1}-P_{\sim 1}^{1}}\left[1-\sum_{k=2}^{n} \frac{P_{\sim 1}^{1}-P_{\sim k}^{k}}{2 P_{k}^{k}-P_{\sim k}^{k}}\right] \text {; }
\end{aligned}
$$




$$
\begin{aligned}
& q_{a^{1}}^{1}=\frac{1}{\Delta}\left[\begin{array}{ccccc}
-\left(P_{1 a}^{1} q^{1}+P_{a}^{1}-c^{\prime}\right) & P_{2}^{1} & P_{3}^{1} & \ldots & P_{n}^{1} \\
0 & 2 P_{2}^{2} & P_{3}^{2} & \ldots & P_{n}^{2} \\
0 & P_{2}^{3} & 2 P_{3}^{3} & \cdots & P_{n}^{3} \\
\vdots & \vdots & \vdots & \vdots & \vdots \\
\vdots & \vdots & \vdots & \vdots & \\
0 & P_{2}^{n} & P_{3}^{n} & \cdots & 2 P_{n}^{n}
\end{array}\right] \\
& =-\frac{1}{\Delta} \frac{\Omega}{2 P_{1}^{1}-P_{\sim 1}^{1}}\left(P_{1 a}^{1} q^{1}+P_{a}^{1}-c^{\prime}\right)\left[1+\sum_{k=2}^{n} \frac{P_{\sim k}^{k}}{2 P_{k}^{k}-P_{\sim k}^{k}}\right] \\
& q_{a^{1}}^{1}=\frac{1}{\Delta}\left[\begin{array}{ccccc}
P_{1}^{1} & -\left(P_{1 a}^{1} q^{1}+P_{a}^{1}-c^{\prime}\right) & P_{3}^{1} & \ldots & P_{n}^{1} \\
2 P_{1}^{2} & 0 & P_{3}^{2} & \ldots & P_{n}^{2} \\
P_{1}^{3} & 0 & 2 P_{3}^{3} & \cdots & P_{n}^{3} \\
\vdots & \vdots & \vdots & \vdots & \vdots \\
P_{1}^{n} & 0 & P_{3}^{n} & \cdots & 2 P_{n}^{n}
\end{array}\right] \\
& =-\frac{1}{\Delta} \frac{\Omega}{2 P_{1}^{1}-P_{\sim 1}^{1}}\left(P_{1 a}^{1} q^{1}+P_{a}^{1}-c^{\prime}\right) \frac{P_{\sim 2}^{2}}{2 P_{2}^{2}-P_{\sim 2}^{2}} ;
\end{aligned}
$$

where

$$
\begin{gathered}
\Omega \equiv \prod_{i=1}^{n}\left(2 P_{i}^{i}-P_{\sim 1}^{i}\right)=\left(2 P_{1}^{1}-P_{\sim 1}^{1}\right)\left(2 P_{2}^{2}-P_{\sim 2}^{2}\right) \cdots\left(2 P_{n}^{n}-P_{\sim n}^{n}\right) \\
\Delta \equiv\left[\begin{array}{cccc}
\pi_{11}^{1} & \pi_{12}^{1} & \cdots & \pi_{1 n}^{1} \\
\pi_{21}^{2} & \pi_{22}^{2} & \cdots & \pi_{2 n}^{2} \\
\vdots & \vdots & \vdots & \vdots \\
\pi_{n 1}^{n} & \pi_{n 2}^{n} & \cdots & \pi_{n n}^{n}
\end{array}\right]=\left[\begin{array}{cccc}
2 P_{1}^{1} & P_{2}^{1} & \cdots & P_{2}^{1} \\
P_{1}^{2} & 2 P_{2}^{2} & \cdots & P_{n}^{2} \\
\vdots & \vdots & \vdots & \vdots \\
\vdots & \vdots & \vdots & \vdots \\
P_{1}^{n} & P_{2}^{n} & \cdots & 2 P_{n}^{n}
\end{array}\right]
\end{gathered}
$$

Similarly,

$$
q_{t}^{i}=\frac{1}{\Delta} \frac{\Omega}{2 P_{i}^{i}-P_{\sim i}^{i}}\left[1-\sum_{k=1, k \neq i}^{n} \frac{P_{\sim i}^{i}-P_{\sim k}^{k}}{2 P_{k}^{k}-P_{\sim k}^{k}}\right], i=1, \ldots, n
$$




$$
\begin{aligned}
q_{a^{i}}^{i} & =\frac{1}{\Delta} \frac{\Omega}{2 P_{i}^{i}-P_{\sim i}^{i}}\left(P_{i a}^{i} q^{i}+P_{a}^{i}-c^{\prime}\right)\left[1+\sum_{k=1, k \neq i}^{n} \frac{P_{\sim k}^{k}}{2 P_{k}^{k}-P_{\sim k}^{k}}\right], i=1, \ldots, n ; \\
q_{a^{i}}^{i} & =\frac{1}{\Delta} \frac{\Omega}{2 P_{i}^{i}-P_{\sim i}^{i}}\left(P_{i a}^{i} q^{i}+P_{a}^{i}-c^{\prime}\right) \frac{P_{\sim j}^{j}}{2 P_{j}^{j}-P_{\sim j}^{j}}, i, j=1, \ldots, n, j \neq i .
\end{aligned}
$$

\section{(Mathematical Appendix B): The Short Run Effects of the Tariff Rate and} the Number of Foreign Firms on Environmental Qualities

According to Equation (10), we know that the environmental qualities are the same in equilibrium. Therefore, we must have $P_{I}^{i}=P_{k}^{k}, P_{\sim i}^{i}=P_{\sim k}^{k}$. Thus, $\Delta=\left(2 P_{i}^{i}-P_{\sim i}^{i}\right)^{n-1}\left[2 P_{i}^{i}+(n-1) P_{\sim i}^{i}\right], \Omega=\left(2 P_{i}^{i}-P_{\sim i}^{i}\right)^{n}$. Substituting Equations (10) and (11) into Equations (4), (5), (6) and (8), we can rewrite the latter four equations as

$$
\begin{gathered}
q_{t}^{i}=\left(2 P_{i}^{i}-P_{\sim i}^{i}\right) \Phi<0, \forall i ; \\
q_{a^{i}}^{i}=-\left(P_{i a}^{i} \bar{q}+P_{a}^{i}-c^{\prime}\right)\left[2 P_{i}^{i}+(n-2) P_{\sim i}^{i}\right] \Phi, \forall i ; \\
q_{a^{i}}^{j}=\left(P_{i a}^{i} \bar{q}+P_{a}^{i}-c^{\prime}\right) P_{\sim i}^{i} \Phi, \quad \forall i, j, j \neq i ; \\
\Pi_{i}^{i}=\left[P_{a}^{i}(\bar{q},(n-1) \bar{q}, \bar{a})-c^{\prime}\right] \bar{q}\left[1+(n-1)\left(P_{\sim i}^{i}\right)^{2} \Phi\right] ; \\
+P_{i a}^{i} \bar{q}^{2}(n-1)\left(P_{\sim i}^{i}\right)^{2} \Phi=0, \forall i ;
\end{gathered}
$$

where $\Phi \equiv 1 /\left(2 P_{i}^{i}-P_{\sim i}^{i}\right)\left[2 P_{i}^{i}+(n-1) P_{\sim i}^{i}\right]>0$. Totally differentiating Equation $\left(8^{\prime}\right)$ with respect to $\bar{a}, n$ and $t$ and rearranging $\Pi_{i}^{i}=0$, we obtain the following comparative static results:

$$
\begin{aligned}
& \left.\frac{d a}{d t}\right|^{s}=-\frac{\Pi_{i t}^{i}}{\Pi_{i i}^{i}} ; \\
& \left.\frac{d a}{d t}\right|^{s}=-\frac{\Pi_{i n}^{i}}{\Pi_{i i}^{i}} ;
\end{aligned}
$$

where

$$
\begin{gathered}
\Pi_{i t}^{i}=q_{t}^{i} \bar{q}\left\{P_{i a}^{i}+(n-1) P_{\sim i a}^{i}\left[1+(n+1)\left(P_{\sim i}^{i}\right)^{2} \Phi\right]\right\} \\
\Pi_{i n}^{i}=-\frac{\bar{q}}{n-1}\left(P_{i a}^{i}-c^{\prime}\right)+P_{\sim i a}^{i} \bar{q}^{2}\left[1+(n-1)\left(P_{\sim i}^{i}\right)^{2} \Phi\right] .
\end{gathered}
$$


Thus, by the above analysis and by Equation (9), it can be shown that

$$
\begin{aligned}
& \left.\frac{d n}{d t}\right|^{2}<(=,>) 0, \text { if } P_{i a}^{i}, P_{\sim i}^{i}>(=,<) 0 ; \\
& \left.\frac{d n}{d t}\right|^{s}>(=,<) 0 \text {, if } P_{i a}^{i}, P_{\sim i a}^{i}>(=,<) 0 .
\end{aligned}
$$

(Mathematical Appendix C): The Long Run Effects of the Tariff Rate on Environmental Qualities and on the Number of Foreign Firms

As in the work in Mathematical Appendix B, we substitute Equations (15) and (16) into Equations (8) and (14); the latter two equations can then be rewritten as

$$
\begin{gathered}
\Pi_{i}^{i}=\left[P_{a}^{i}\left(q^{*},\left(n^{*}-1\right) q^{*}, a^{*}\right)-c^{\prime}\right] q^{*}\left[1+\left(n^{*}-1\right)\left(P_{\sim i}^{i}\right)^{2} \Phi\right] ; \\
+P_{i a}^{i}\left(q^{*}\right)^{2}\left(n^{*}-1\right)\left(P_{\sim i}^{i}\right)^{2} \Phi=0, \forall i \\
\Pi^{i}=P^{i}\left(q^{*},\left(n^{*}-1\right) q^{*}, a^{*}\right) q^{*}-c\left(a^{*}\right) q^{*}-t q^{*}=0, \quad \forall i .
\end{gathered}
$$

Totally differentiating Equations (8") and (14') with respect to $a^{*}, n^{*}$ and $t$ and rearranging Equations $\left(4^{\prime}\right)$ and $\left(8^{\prime \prime}\right)$, we find:

where

$$
\left[\begin{array}{cc}
\Pi_{i i}^{i} & \Pi_{i n}^{i} \\
\Pi_{i}^{i} & \Pi_{n}^{i}
\end{array}\right]\left[\begin{array}{c}
d a \\
d n
\end{array}\right]=\left[\begin{array}{c}
-\Pi_{i t}^{i} \\
-\Pi_{t}^{i}
\end{array}\right] d t,
$$

$$
\begin{aligned}
& \Pi_{i}^{i t}=-\frac{q^{*}}{n^{*}-1}\left(P_{a}^{i}-c^{\prime}\right)+P_{\sim i a}^{i}\left(q^{*}\right)^{2}\left[1+\left(n^{*}-1\right)\left(P_{\sim i}^{i}\right)^{2} \Phi\right] ; \\
& \Pi_{i}^{i t}=q_{t}^{i} q^{*}\left\{P_{i a}^{i}+\left(n^{*}-1\right) P_{\sim i a}^{i}\left[1+\left(n^{*}+1\right)\left(P_{\sim i}^{i}\right)^{2} \Phi\right]\right\} ; \\
& \Pi_{i}^{i}=0 \\
& \Pi_{n}^{i}=P_{\sim i}^{i}\left(q^{*}\right)^{2}<0 \\
& \Pi_{t}^{i}=-2 P_{i}^{i}\left(2 P_{i}^{i}-P_{\sim i}^{i}\right) q^{*} \Phi<0 .
\end{aligned}
$$

Applying Cramer'srule, we obtain the effects of the tariff rate on environmental qualities and on the number of foreign firms in the long run, which are

$$
\left.\frac{d a}{d t}\right|^{l}=-\frac{1}{\Pi_{i i}^{i}}\left[\Pi_{i t}^{i}+\frac{2 P_{i}^{i}\left(2 P_{i}^{i}-P_{\sim i}^{i}\right) \Phi}{P_{\sim i}^{i} q^{*}} \Pi_{i n}^{i}\right] ;
$$




$$
\left.\frac{d n}{d t}\right|^{l}=\frac{2 P_{i}^{i}\left(2 P_{i}^{i}-P_{\sim i}^{i}\right) \Phi}{P_{\sim i}^{i} q^{*}}<0 .
$$

Thus, by the above analysis and Equation (9), it can be proved that $\left.(d n / d t)\right|^{l}<0$, and that if $P_{i a}^{i}$ and $P_{\sim i a}^{i}>(=,<) 0$, then $\left.(d n / d t)\right|^{l}<(=,>) 0$.

(Mathematical Appendix D): The Short Run Effects of Environmental Qualities and the Number of Foreign Firms on the Optimal Tariff Rate

Differentiating Equation (24) with respect to $t, \hat{a}$ and $n$ and rearranging $G_{t}=0$, we obtain the short run effects of environmental qualities and the number of foreign firms on the optimal tariff rate:

$$
\begin{gathered}
\left.\frac{d t}{d a}\right|^{s}=-\frac{G_{t a}}{G_{t t}} \\
=\frac{1}{2-P_{i}^{i} q_{t}^{i}}\left\{\left(1-P_{i}^{i} q_{t}^{i}\right)\left(P_{a}^{i}-c^{\prime}\right)+\beta D^{\prime} e^{\prime}-\hat{q}\left[P_{i}^{i} q_{t}^{i} P_{i a}^{i}+(n-1) P_{\sim i a}^{i}\right]\right\} \\
\left.\frac{d t}{d n}\right|^{s}=-\frac{G_{t n}}{G_{t t}} \\
=-\frac{P_{\sim i}^{i} \hat{q}}{2-P_{i}^{i} q_{t}^{i}} ;
\end{gathered}
$$

where

$$
\begin{gathered}
\left.G_{t t} \equiv \frac{\partial^{2} G\left(a^{1}, \ldots, a^{n}, t\right)}{\partial t^{2}}\right|_{a^{i}=\hat{a}, \forall i} \\
=n q_{t}^{i}\left(2-P_{i}^{i} q_{t}^{i}\right)<0 ; \\
\left.G_{t a} \equiv \sum_{i=1}^{n} \frac{\partial^{2} G\left(a^{1}, \ldots, a^{n}, t\right)}{\partial t \partial a^{i}}\right|_{a^{i}=\hat{a}, \forall i} \\
=-n q_{t}^{i}\left\{\left(1-P_{i}^{i} q_{t}^{i}\right)\left(P_{a}^{i}-c^{\prime}\right)+\beta D^{\prime} e^{\prime}-\hat{q}\left[P_{i}^{i} q_{t}^{i} P_{i a}^{i}+(n-1) P_{\sim i a}^{i}\right]\right\} \\
\left.G_{t n} \equiv \frac{\partial^{2} G\left(a^{1}, \ldots, a^{n}, t\right)}{\partial t \partial n}\right|_{i^{i}=\hat{a}, \forall i} \\
=n q_{t}^{i} P_{\sim i}^{i} \hat{q}>0 .
\end{gathered}
$$

Since the demand functions are assumed to be linear, $1-P_{i}^{i} q_{t}^{i}=\left[P_{i}^{i}+(n-1) P_{\sim i}^{i}\right]$ $q_{t}^{i}>0$ and $-P_{i}^{i} q_{t}^{i}=\left[3 P_{i}^{i}+2\left(n-1 P_{\sim i}^{i}\right] q_{t}^{i}>0\right.$ Therefore, $\left.(d t / d n)\right|^{s}>0$ always holds. It is more likely that $\left.(d t / d n)\right|^{s}<0$ will hold if $P_{i a}^{i}, P_{\sim i a}^{i}>0$ and get larger, if 
$P_{i a}^{i}$ gets smaller, or if $c^{\prime}, \beta, D^{\prime}$ and $\left|e^{\prime}\right|$ get larger. Otherwise, $\left.(d t / d n)\right|^{s}<0$ is more likely to hold.

\section{(Mathematical Appendix E): The Long Run Effects of Environmental Qualities on the Optimal Tariff Rate and on the Number of Foreign Firms}

Substituting $\breve{n}, \breve{t}$ and $\breve{q}$ into Equations (24) and (27), we can rewrite the latter two equations as:

$$
\begin{gathered}
G_{t}=\check{n}\left[\breve{q}\left(1-P_{i}^{i} q_{t}^{i}\right)+q_{t}^{i}\left(t-\beta D^{\prime} e\right)\right]=0 ; \\
\Pi_{t}=P^{i}(\check{q},(\breve{n}-1) \breve{q}, \hat{a}) \breve{q}-c(\hat{a}) \breve{q}-c(\hat{a}) \breve{q}-\breve{t} \check{q}=0, \quad \forall i .
\end{gathered}
$$

Letting Equations (24') and (27') be totally differentiated with respect to $\breve{t}, \check{n}$ and $\breve{a}$, we have

where

$$
\left[\begin{array}{c}
G_{t t} G_{t n} \\
\hat{\Pi}_{t}^{i} \hat{\Pi}_{n}^{i}
\end{array}\right]\left[\begin{array}{c}
d t \\
d n
\end{array}\right]=\left[\begin{array}{c}
-G_{t a} \\
\hat{\Pi_{n}^{i}}
\end{array}\right] d a
$$

$$
\begin{gathered}
\left.\hat{\Pi}_{t}^{i} \equiv \frac{\partial \Pi^{i}\left(a^{1}, \ldots, a^{n}, t\right)}{\partial t}\right|_{a^{i}=\hat{a}, \forall i}=-2 q_{t}^{i} P_{i}^{i} \breve{q}<0 ; \\
\left.\hat{\Pi}_{a}^{i} \equiv \sum_{j=1}^{n} \frac{\partial \Pi^{i}\left(a^{1}, \ldots, a^{n}, t\right)}{\partial a^{j}}\right|_{a^{i}=\hat{a}, \forall i}=q_{t}^{i} \grave{q}\left[2 P_{i}^{i}\left(P_{a}^{i}-c^{\prime}\right)-(\tilde{n}-1) P_{\sim i}^{i} P_{i a}^{i} \breve{q}\right] \\
\left.\hat{\Pi}_{n}^{i} \equiv \frac{\partial \Pi^{i}\left(a^{1}, \ldots, a^{n}, t\right)}{\partial n}\right|_{a^{i}=\hat{a}, \forall i} P_{\sim i}^{i} \breve{q}^{2}<0 .
\end{gathered}
$$

Applying Cramer'srule, we derive the long run effects of environmental qualities on the tariff rate and on the number of foreign firms:

$$
\begin{aligned}
\left.\frac{d t}{d a}\right|^{l}=\frac{1}{H}\left(-G_{t a} \hat{\Pi}_{n}^{i}+G_{t n} \hat{\Pi}_{a}^{i}\right) \\
=\frac{1}{2+P_{i}^{i} q_{t}^{i}} \\
\quad\left\{\left(1+P_{i}^{i} q_{t}^{i}\right)\left(P_{a}^{i}-c^{\prime}\right)+\beta D^{\prime} e^{\prime}-\hat{q} q_{t}^{i}\left[P_{i}^{i}+(\check{n}-1) P_{\sim i}^{i}\right] P_{i a}^{i}-\check{q}(\check{n}-1) P_{\sim i a}^{i}\right\} ;
\end{aligned}
$$




$$
\begin{aligned}
& \left.\frac{d n}{d a}\right|^{l}=\frac{1}{H}\left(-G_{t t} \hat{\Pi}_{n}^{i}+G_{t a} \hat{\Pi}_{t}^{i}\right) \\
& =-\frac{P_{i}^{i} q_{t}^{i}}{P_{\sim i}^{i} \check{q}\left(2+P_{i}^{i} q_{t}^{i}\right)}\left[2\left(P_{a}^{i}-c^{\prime}\right)-2 \beta D^{\prime} e^{\prime}+\check{q} P_{i a}^{i}\right]
\end{aligned}
$$

where $H \equiv G_{t t} \hat{\Pi}_{n}^{i}-G_{t n} \hat{\Pi}_{n}^{i}=\hat{n} q_{t}^{i} P_{\sim i}^{i} \breve{q}^{2}\left(2+P_{i}^{i} q_{t}^{i}\right)>0$

Therefore, it can be proved that it is more likely for $\left.(d t / d n)\right|^{l}<0$ to hold if $P_{i a}^{i}, P_{\sim i a}^{i}>0$ and get higher, if $P_{a}^{i}$ gets smaller, or if $c^{\prime}, \beta, D^{\prime}$ and $\left|e^{\prime}\right|$ get larger. It is more likely for $\left.(d t / d n)\right|^{l}>0$ to hold if $P_{i a}^{i}>0$ and gets larger, if $P_{a}^{i}$, $P_{a}^{i}, \beta, D^{\prime}$, and $\left|e^{\prime}\right|$ get larger, or if $c^{\prime}$ gets smaller.

Date accepted: January 2001

\section{References}

Anderson, K. (1992), “Agricultural Trade Liberalization and the Environment: A Global Perspective," World Economy, 15, 153-171.

Blend, J.R. and E.O. van Ravenswaay (1999), "Measuring Consumer Demand for Ecolabeled Apples," American Journal of Agricultural Economics, 81, 1072-1077.

Brander, J.A. and B.J. Spencer (1984), "Trade Warfare: Tariffs and Cartels," Journal of International Economics, 16, 227-242.

Chan, R.Y.K. (2000), "The Effectiveness of Environmental Advertising: The Role of Claim Type and the Source Country Green Image," International Journal of Advertising, 19, 349-375.

Conrad, K. (1993), "Taxes and Subsidies for Pollution-Intensive Industries as Trade Policy," Journal of Environmental Economics and Management, 25, 121-135.

Conrad, K. and J. Wang (1993), "The Effect of Emission Taxes and Abatement Subsidies on Market Structure,” International Journal of Industrial Organization, 11, 499-518. Copeland, B.R. (1996), "Pollution Content Tariffs, Environmental Rent Shifting, and the Control of Cross-Border Pollution," Journal of International Economics, 40, 459-476. D’Arge, R.C. and A.V. Kneese (1972), "Environmental Quality and International Trade," International Organization, 26, 419-465.

Das, S.P. and S. Donnenfeld (1987), "Trade Policy and Its Impact on Quality of Imports," Journal of International Economics, 23, 77-95.

Jayadevappa, R. and S. Chhatre (2000), "International Trade and Environmental Quality: A Survey," Ecological Economics, 32, 175-194.

Kennedy, P.W. (1994), "Equilibrium Pollution Taxes in Open Economies with Imperfect Competition," Journal of Environmental Economics and Management, 27, 49-63. 
Koo, A.Y.C. (1974), "Environmental Repercussions and Trade Theory," Review of Economics and Statistics, 56, 235-244.

Krishna, K. (1987), "Tariffs versus Quotas with Endogenous Quality," Journal of International Economic, 23, 97-122.

Krutilla, K. (1991), "Environmental Regulation in an Open Economy," Journal of Environmental Economics and Management, 20, 127-142.

Ludema, R.D. and I. Wooton (1994), "Cross-Border Externalities and Trade Liberalization: The Strategic Control of Pollution," Canadian Journal of Economics, 27, 950966.

Ludema, R.D. and I. Wooton (1997), "International Trade Rules and Environmental Cooperation under Asymmetric Information," International Economic Review, 38, 605-625.

Lutz, E. (1992), “Agricultural Trade Liberalization, Price Changes, and Environmental Effects," Environmental and Resource Economics, 2, 79-89.

Markusen, J.R. (1975), “International Externalities and Optimal Tax Structures," Journal of International Economics, 5, 15-29.

Matoo, A. and H.V. Singh (1994), "Eco-labelling: Policy Considerations," Kyklos, 47, 53 65.

McGuire, M.C. (1982), “Regulation, Factor Rewards, and International Trade,” Journal of Public Economics, 17, 335-354.

Merrifield, J.D. (1988), "The Impact of Selected Abatement Strategies on Transnational Pollution, the Terms of Trade, and Factor Rewards: A General Equilibrium Approach," Journal of Environmental Economics and Management 15, 259-284.

Perroni, C. and R.M. Wigle (1994), "International Trade and Environmental Quality: How Important are the Linkages ?" Canadian Journal of Economics 27, 551-567.

Pethig, R. (1976), "Pollution, Welfare, and Environmental Policy in the Theory of Comparative Advantage," Journal of Environmental Economics and Management, 2, 160-169.

Rosendorff, B.P. (1996), "Voluntary Export Restraints, Antidumping Procedure, and Domestic Politics," American Economic Review, 86, 544-561.

Sartzetakis, E. S. and C. Constantatos (1995), "Environmental Regulation and International Trade," Journal of Regulatory Economics, 8, 61-72.

Schmutzler, A. and L.H. Goulder (1997), "The Choice between Emission Taxes and Output Taxes under Imperfect Monitoring," Journal of Environmental Economics and Management, 32, 51-64.

Stevens, J. M. Ahmad and S. Rudell (1998), "Forest Products Certification: A Survey of Manufacturers," Forest Products Journal, 48, 43-49.

Swallow, S.K. and R.A. Sedjo (2000), "Eco-Labeling Consequences in General Equilibrium: A Graphical Assessment," Land Economics, 76, 28-36.

van Bergeijk, P.A.G. (1991), "International Trade and the Environmental Challenge," Journal of World Trade 25, 105-115.

Walter, I. (1972), "Environmental Control and Patterns of International Trade and 
Investment: An Emerging Policy Issue,' Banca Nezienale Del Lavoro Quarterly Review, 100, 82-106.

Wessells, C., J. Kline and J.G. Anderson (1996), "Seafood Safety Perceptions and Their

Effects on Anticipated Consumption under Varying Information Treatments," Agricultural and Resource Economics Review, 25, 12-21.

Wessells, C., R.J. Johnston and H. Donath (1999), "Assessing Consumer Preferences for

Ecolabeled Seafood: The Influence of Species, Certifier, and Household Attributes," American Journal of Agricultural Economics, 81, 1084-1089

Whalley, J. (1991), “The Interface between Environmental and Trade Policies," Economic Journal, 101, 180-189.

World Trade Organization (1996), Report of the WTO Committee on Trade and Environment.

World Trade Organization (1997), Report of the WTO Committee on Trade. 